\title{
Prevalence of Helicobacter pylori infection and gastric preneoplastic lesions in patients admitted for upper gastro-intestinal endoscopy in Cotonou (Benin Republic)
}

\begin{abstract}
Infection with Helicobacter pylori (H. pylori) is common in developing countries such as Benin. This germ can cause several gastroduodenal diseases such as gastritis, ulcer, adenocarcinoma or gastric MALT lymphoma. This study aimed to determine the prevalence of $H$. pylori infection and gastric pre-neoplastic histological lesions in patients admitted for upper gastrointestinal endoscopy (UGE) and to identify factors associated with this infection.

Methods: This was a cross-sectional descriptive and analytical study, with prospective data collection, conducted from October 2014 to December 2015. We included all patients admitted to Menontin Hospital for UGE in whom a gastric biopsy has been done. H. pylori research was conducted in anatomy-pathology, either in a medical laboratory in Cotonou or at the CERBA laboratory in Paris, France, depending on the patient's choice. The microscopic study was carried out after staining with Haematoxyline-Eosine-Safran (HES) and the search for $H$. pylori using Giemsa staining.
\end{abstract}

Results: H. pylori was investigated in 137 patients, 67 men (48.9\%) and 70 women (51.1\%). The mean age was $48.3 \pm 14$.6years with extremes of 10 and 83 years. Some patients had had at least one previous $H$. pylori eradication treatment (63 cases or $46 \%$ ). For the general population, the test was positive in 98 cases, i.e. a prevalence of $71.5 \%$. Depending on whether or not patients had been pre-treated for H. pylori, the test was positive in 40 out of $63(63.5 \%)$ pre-treated patients, versus 58 out of $74(78.4 \%)$ patients who were naïve to any eradication treatment $(\mathrm{p}=0.057)$. The pre-neoplastic lesions noted were gastric atrophy in 35 patients (including $25 \mathrm{H}$. pylori positive), intestinal metaplasia in 13 patients (including 10 $\mathrm{H}$. pylori positive) and low grade dysplasia in 14 patients (including $12 \mathrm{H}$. pylori positive); high grade dysplasia was found in one patient who was $H$. pylori negative. Only the type of prior eradicant treatment appeared to be associated with $H$. pylori infection $(\mathrm{p}=0.182)$.

Conclusion: H. pylori infection is common in our patients admitted for upper gastrointestinal endoscopy. Gastric atrophy was the most common pre-neoplastic lesion.

Keywords: Helicobacter pylori, upper gastrointestinal endoscopy, gastric preneoplastic lesions, cotonou
Volume II Issue 6 - 2020

\author{
Aboudou Raïmi Kpossou,' Benoît \\ Kouwakanou, ${ }^{2}$ Falilatou Séidou, ${ }^{3}$ Khadidjatou \\ Saké Alassane, ${ }^{4}$ Rodolph Koffi Vignon, \\ Comlan N'déhougbèa Martin Sokpon,' Carin \\ Ahouada, ${ }^{5}$ Vincent Zoundjiekpon, ${ }^{6}$ Fadel \\ Sourokou, ${ }^{7}$ Nicolas Kodjoh, ${ }^{8}$ Jean Séhonou' \\ 'Department of Hepato-Gastroenterology, National and \\ University Hospital Hubert Koutoukou Maga (CNHU-HKM), \\ Benin Republic \\ ${ }^{2}$ Department of Hepato-Gastroenterology, Mohammed VI \\ University Hospital of Marrakech, Morocco \\ ${ }^{3}$ Department of Anatomopathology and Cytopathology, Faculty \\ of Health Sciences, Benin Republic \\ ${ }^{4}$ Department of internal medicine, Borgou-Alibori University \\ Hospital, Benin Republic \\ ${ }^{5}$ Medicine Department,Allada Zone Hospital, Benin Republic \\ ${ }^{6}$ Department of Hepato-Gastroenterology and Geriatrics, \\ Olomouc University Hospital, Czech Republic \\ IInternational Clinic of Cotonou Aupiais (CICA), Benin Republic \\ ${ }^{8}$ Archangel Clinic, Agblangandan - Sèmè kpodji, Benin Republic
}

Correspondence: Dr Aboudou Raïmi Kpossou, Department of Hepato-Gastroenterology, National and University Hospital Hubert Koutoukou Maga (CNHU-HKM), Benin Republic, Tel 0022966181939, Email kpossou.raimi@yahoo.fr

Received: October 27, 2020 | Published: November 13, 2020

\section{Introduction}

Infection with Helicobacter pylori (H. pylori) occurs in half of the world's population. ${ }^{1}$ Its prevalence varies considerably according to geographic location, ethnicity, age, and socio-economic factors; it is high in developing countries and lower in developed countries. ${ }^{1,2}$ It is $20-30 \%$ in industrialized countries and $70-90 \%$ in developing countries where it is a real public health problem. ${ }^{1}$ This is confirmed by most recent studies carried out around the world and particularly in Africa, notably in Nigeria with a prevalence of $80 \%$ in $2020,{ }^{3}$ $88 \%$ in Ghana in $2017,{ }^{4} 70.41 \%$ and $93.1 \%$ in 2015 respectively in $\mathrm{Togo}^{5}$ and Congo Brazzaville, ${ }^{6} 70.8 \%$ in Burundi in 2014, $66.12 \%$ in Egypt in $2019,{ }^{8} 63.8 \%$ in Morocco in $2016^{9}$ and $71.43 \%$ in Algeria. ${ }^{10}$ In contrast, the prevalence of $H$. pylori is declining in developed countries, around 24-32\% in Central and Northern Europe excluding non-European immigrants. ${ }^{1,11}$ The high prevalence of $H$. pylori infection in developing countries has been associated with overcrowding, poor housing, poor sanitation and lack of safe drinking water. ${ }^{4,12} H$. pylori infection occurs in childhood, mainly in the first fiveyears of life, and is transmitted primarily by the fecal-oral and/ or oral-oral route. ${ }^{13}$ It usually goes unnoticed, asymptomatic and can persist throughout life if not eradicated by adequate therapy. Its role in the genesis of various gastroduodenal pathologies such as gastritis, dyspeptic syndromes, gastric or duodenal ulcer, mucosa-associated lymphoid tissue lymphoma (MALT) and gastric adenocarcinoma is currently proven..$^{14}$ It is the only bacterium currently recognized as a human carcinogen and classified as such since 1994 by the International Agency for Research on Cancer, i.e. the World Health Organization. ${ }^{15}$

Several methods exist to detect $H$. pylori. Some are invasive, such as methods requiring gastric biopsies taken during gastroscopy (pathological anatomy, culture, polymerase chain reaction, rapid urease test). Others are non-invasive (labeled urea breath test, antigen detection in stool, serology). ${ }^{14,16}$ Anatomo-pathological examination of gastric biopsies, apart from staining for $H$. pylori, offers the advantage of good sensitivity and specificity, and also allows the detection of pre-neoplastic lesions (intestinal metaplasia or dysplasia) 
and the typing of gastritis. ${ }^{14,17}$ In Benin, the search for $H$. pylori by anatomo-pathological examination was not common before the year 2012, and little data exists on this subject. ${ }^{18}$ Two prospective studies of $H$. pylori testing in Cotonou in patients admitted for UGE reported a prevalence of $56.41 \%$ in $1991^{19}$ and $66.5 \%$ in $1996,{ }^{20}$ respectively, and a retrospective study from 2007 to 2016 reported a prevalence of $56 \%$ in Cotonou for $H$. pylori gastritis. ${ }^{18}$

The aim of this study was to determine the prevalence of $H$. pylori infection and gastric pre-neoplastic histological lesions in patients admitted for upper gastrointestinal endoscopy (UGE) and to identify factors associated with this infection.

\section{Methods}

This was a descriptive and analytical cross-sectional study with prospective data collection during the period from October 2014 to December 2015. We included all patients admitted to Menontin Hospital for UGE and in whom gastric biopsies could be taken. Patients were either naïve to any $H$. pylori eradication treatment, or may have already had one or more eradication treatments. The $H$. pylori research was performed by anatomo-pathological examination, either in a medical laboratory in Cotonou (Benin Republic) or at the CERBA laboratory in Paris (France), depending on the patient's choice. The microscopic study was done after hematoxylin-eosinsafran (HES) staining and the search for H. pylori using Giemsa staining.

A standardized survey form was used for data collection. The main dependent variable was $H$. pylori infection on the anatomo- pathological examination of the gastric biopsy results. The other dependent variable was gastric pre-neoplastic lesions (atrophy, intestinal metaplasia and low or high-grade dysplasia). The independent variables were sociodemographic, clinical, endoscopic and therapeutic.

Statistical analysis was performed using SPSS 18.0. The analysis of the qualitative variables was performed by Chi2 and Fischer exact tests. A $\mathrm{p} \leq 0.05$ was considered statistically significant. The association between $H$. pylori infection and the different variables was studied by logistic regression in univariate and multivariate analysis to confirm the involvement of the studied variables in $H$. pylori infection.

\section{Results}

\section{Characteristics of the study population}

Our study involved 137 patients who all underwent upper gastrointestinal endoscopy with gastric biopsy for pathological examination, including 67 men (48.9\%) and 70 women (51.1\%). The mean age was $48.3 \pm 14$.6years with extremes of 10years and 83years. One hundred and sixteen patients $(84.7 \%)$ lived as a couple compared to $14(10.2 \%)$ who were single. Seventy-seven patients $(56.6 \%)$ had a university education compared to $6(4.4 \%)$ who had no schooling. More than half of the study population (74 patients, i.e. $54.4 \%$ ) was employees. And more than $3 / 4$ were Christians (122 patients or $89.1 \%$ ) (Table 1). As co-morbidities, 31 patients $(22.6 \%)$ were hypertensive, 29 patients $(21.2 \%)$ were obese; diabetes and history of gastric ulcer in first-degree relatives were found in 5 patients $(3.7 \%)$ (Table 2).

Table I Distribution of socio-demographic characteristics of the study population according to whether or not they carry $H$. pylori infection

\begin{tabular}{|c|c|c|c|}
\hline \multirow{2}{*}{ Socio-demographic characteristics } & \multicolumn{2}{|l|}{ H. pylori } & \multirow{2}{*}{$\mathbf{p}$} \\
\hline & Yes $[n=98(71,5 \%)]$ & No $[n=39(28,5 \%)]$ & \\
\hline Age (Average in years) & 47.3 & 50.9 & 0.1901 \\
\hline Gender & & & 0.7089 \\
\hline Male & $49(35.8 \%)$ & $18(13.1 \%)$ & \\
\hline Female & $49(35.8 \%)$ & $21(26.9 \%)$ & \\
\hline Marital Status & & & 0.6392 \\
\hline Single & II (8.0\%) & $3(2.2 \%)$ & \\
\hline As A Couple & $83(60.6 \%)$ & $33(24.1 \%)$ & \\
\hline Divorced & $\mathrm{I}(0.7 \%)$ & 00 & \\
\hline Widow(Er) & $3(2.2 \%)$ & $3(2.2 \%)$ & \\
\hline Level of Edducation & & & 0.5039 \\
\hline Primary & $16(11.8 \%)$ & $6(4.4 \%)$ & \\
\hline Secondary & $19(14.0 \%)$ & $12(8.8 \%)$ & \\
\hline Superior & $58(42.7 \%)$ & $19(14.0 \%)$ & \\
\hline Unschooled & $4(2.9 \%)$ & $2(1.5 \%)$ & \\
\hline Profession & & & 0.6326 \\
\hline Liberal & $3 \mathrm{I}(22.8 \%)$ & $13(9.6 \%)$ & \\
\hline Reseller & $10(7.4 \%)$ & $\mathrm{I}(0.7 \%)$ & \\
\hline Employee & $5 I(37.5 \%)$ & $23(16.9 \%)$ & \\
\hline Pupil/Student & $5(3.7 \%)$ & $2(1.5 \%)$ & \\
\hline
\end{tabular}




\begin{tabular}{llll}
\hline Table Continued... & & & \\
\hline \multirow{2}{*}{ Socio-demographic characteristics } & H. pylori & & \\
\cline { 2 - 3 } & Yes $[\mathbf{n}=\mathbf{9 8}(\mathbf{7 1}, \mathbf{5 \%})]$ & No $[\mathbf{n = 3 9 ( 2 8 , 5 \% ) ]}$ & \\
\hline Religion & & & 0.2336 \\
Islam & $9(6.6 \%)$ & $5(3.7 \%)$ & \\
Christianity & $89(64.9 \%)$ & $33(24.1 \%)$ & \\
Animism & 00 & $\mathrm{I}(0.7 \%)$ & \\
\hline
\end{tabular}

Table 2 Distribution of medical history according to whether or not $H$. pylori infection was carried

\begin{tabular}{|c|c|c|c|}
\hline \multirow{2}{*}{ Background } & \multicolumn{2}{|l|}{ H. pylori } & \multirow{2}{*}{$\mathbf{p}$} \\
\hline & Yes $[n=98(71,5 \%)]$ & No $[n=39(28,5 \%)]$ & \\
\hline Obesity & & & 0.8173 \\
\hline Yes & $20(14.6 \%)$ & $9(6.6 \%)$ & \\
\hline No & $78(56.9 \%)$ & $30(21.9 \%)$ & \\
\hline Diabetes & & & 1.000 \\
\hline Yes & $4(2.9 \%)$ & $\mathrm{I}(0.7 \%)$ & \\
\hline No & $94(68.6 \%)$ & $38(27.7 \%)$ & \\
\hline $\mathrm{Hta}$ & & & 0.3680 \\
\hline Yes & $20(14.6 \%)$ & II(8.0\%) & \\
\hline No & $78(56.9 \%)$ & $28(20.4 \%)$ & \\
\hline \multicolumn{4}{|l|}{ Cirrhosis } \\
\hline Yes & 00 & 00 & \\
\hline No & $98(71.5 \%)$ & $39(28.5 \%)$ & \\
\hline \multicolumn{4}{|l|}{ Hiv } \\
\hline Yes & 00 & 00 & \\
\hline No & $98(71.5 \%)$ & $39(28.5 \%)$ & \\
\hline Alcoholism & & & 0.2847 \\
\hline Yes & 00 & $0 \mathrm{I}(0.7 \%)$ & \\
\hline No & $98(71.5 \%)$ & $38(27.7 \%)$ & \\
\hline \multicolumn{3}{|c|}{ Gastric Ulcer Grade I } & 0.6229 \\
\hline Yes & $3(2.2 \%)$ & $2(1.5 \%)$ & \\
\hline No & $95(69.3 \%)$ & $37(27.0 \%)$ & \\
\hline \multicolumn{3}{|c|}{ Gastric Cancer Grade I } & 1.000 \\
\hline Yes & $2(1.5 \%)$ & $\mathrm{I}(0.7 \%$ & \\
\hline No & $96(70.1 \%)$ & $38(27.7 \%)$ & \\
\hline \multicolumn{3}{|c|}{ Other Background } & 0.4146 \\
\hline Yes & $5(3.7 \%)$ & $3(2.2 \%)$ & \\
\hline No & $92(64.7 \%)$ & $36(26.5 \%)$ & \\
\hline
\end{tabular}


The main clinical manifestations that motivated the UGE were diverse but dominated by epigastric disorders in 92 patients $(67.2 \%)$, painful dyspepsia in 25 patients $(18.3 \%)$, painless dyspepsia in 8 patients $(5.8 \%)$, non-specific abdominal pain in 5 patients $(3.7 \%)$, and upper GI hemorrhage in 14 patients $(10.2 \%)$.

\section{Prevalence of $H$. pylori infection and gastric pre- neoplastic lesions}

The prevalence of $H$. pylori in the study population was $71.5 \%$ (98/137). Among the 98 patients with H. pylori, 58 (59.2\%) were naïve to any eradication treatment, while $40(40.8 \%)$ had previously received at least one $H$. pylori eradication treatment (Table III) Depending on whether or not the patients had been pre-treated for $H$. pylori, the search for $H$. pylori was positive in 40 pre-treated patients out of $63(63.5 \%)$ compared to 58 patients out of $74(78.4 \%)$ for patients naïve to any eradicant treatment, with a $\mathrm{p}=0.057$ (nonsignificant difference). According to the place of analysis, for samples sent to France, the search for H. pylori was positive in 31 cases (73.8\%), and for those tested in Benin it was positive in 67 cases (70.5\%), with a $\mathrm{p}=0.693$ (non-significant difference)

Histologically, the pre-neoplastic lesions noted were gastric atrophy in 35 patients (including $25 \mathrm{H}$. pylori positive), intestinal metaplasia in 13 patients (including $10 \mathrm{H}$. pylori positive) and low grade dysplasia in 14 patients (including $12 \mathrm{H}$. pylori positive); high grade dysplasia was found in one patient who was $H$. pylori negative. One case of gastric adenocarcinoma was noted.

\section{Factors associated with $\mathrm{H}$. pylori infection}

H pylori were present in patients with an average age of 47.26years. However, neither age $(\mathrm{p}=0.1901)$ nor $\mathrm{sex}(\mathrm{p}=0.7089)$ was associated with $H$. pylori infection (Table 1). Furthermore, in our study, other socio-demographic factors such as marital status $(\mathrm{p}=0.6392)$, religion (0.2336), occupation ( $\mathrm{p}=0.6326)$, and education $(\mathrm{p}=0.5039)$ were not associated with $H$. pylori infection (Table 2). Similarly, none of the co-morbidities studied were associated with $H$. pylori infection (Table 2). Furthermore, endoscopically, the prevalence of $H$. pylori appeared to be higher in cases of pangastritis $(65.69 \%)$, but this association was not statistically significant $(\mathrm{p}=0.7243)$ (Tables $3 \& 4)$. Previous treatment was not associated with $H$. pylori infection $(\mathrm{p}=0.057)$. However, the type of previous treatment appears to be statistically associated $(\mathrm{p}=0.0182)$, with triple therapy including Amoxicillinmetronidazole being associated with more positive cases of $H$. pylori infection (30.16\%) (Table 3).

Table 3 Distribution of $H$. pylori infection by prior treatment status

\begin{tabular}{|c|c|c|c|}
\hline \multirow{2}{*}{$\begin{array}{l}\text { Previous } H \text {. pylori eradication } \\
\text { treatment }\end{array}$} & \multicolumn{2}{|l|}{ H. pylori } & \multirow{2}{*}{$\mathbf{p}$} \\
\hline & Yes $[n=98(71.5 \%)]$ & No $[n=39(28,5 \%)]$ & \\
\hline Previous Treatment For H. Pylori & & & 0.0602 \\
\hline Yes & $40(29.2 \%)$ & $23(16.8 \%)$ & \\
\hline No & $58(42.3 \%)$ & $16(11.7 \%)$ & \\
\hline Type of Previous Treatment & & & 0.0182 \\
\hline Amoxicillin-Metronidazol & $19(30.2 \%)$ & $4(6.4 \%)$ & \\
\hline Amoxicillin-Clarithromycin & $7(11.1 \%)$ & II(I7.5\%) & \\
\hline Clarithromycin-Metronidazol & $3(4.8 \%)$ & 00 & \\
\hline Sequential & $10(4.8 \%)$ & $7(11.1 \%)$ & \\
\hline Amoxicillin-Levofloxacin & 00 & 00 & \\
\hline Bismuth Therapy & $2(3.2 \%)$ & 00 & \\
\hline
\end{tabular}

Table 4 Distribution of $H$. pylori infection by endoscopic appearance

\begin{tabular}{|c|c|c|c|}
\hline \multirow{2}{*}{ Endoscopic data } & \multicolumn{2}{|l|}{ H. pylori } & \multirow{2}{*}{$\mathbf{p}$} \\
\hline & Yes $[n=98(71.5 \%)]$ & No $[n=39(28.5 \%)]$ & \\
\hline Antral Gastritis & & & 0.4453 \\
\hline Yes & $8(5.8 \%)$ & $\mathrm{I}(0.7 \%)$ & \\
\hline No & $90(65.7 \%)$ & $38(27.7 \%)$ & \\
\hline Fundic Gastritis & & & 0.4898 \\
\hline Yes & $I(0.7 \%)$ & $\mathrm{I}(0.7 \%)$ & \\
\hline No & $97(70,8 \%)$ & $38(27.7 \%)$ & \\
\hline Pangastritis & & & 0.7243 \\
\hline Yes & $90(65.7 \%)$ & $37(27.0 \%)$ & \\
\hline No & $8(5.8 \%)$ & $2(1.5 \%)$ & \\
\hline
\end{tabular}




\begin{tabular}{|c|c|c|c|}
\hline \multirow{2}{*}{ Endoscopic data } & \multicolumn{2}{|l|}{ H. pylori } & \multirow{2}{*}{$\mathbf{p}$} \\
\hline & Yes $[n=98(71.5 \%)]$ & No $[n=39(28.5 \%)]$ & \\
\hline Gastric Ulcer & & & 0.5404 \\
\hline Yes & $9(6.6 \%)$ & $5(3.7 \%)$ & \\
\hline No & $89(65.0 \%)$ & $34(24.8 \%)$ & \\
\hline Duodenal Ulcer & & & 0.6743 \\
\hline Yes & $5(3.7 \%)$ & $\mathrm{I}(0.7 \%)$ & \\
\hline No & $93(67.9 \%)$ & $38(27.7 \%)$ & \\
\hline Gastric Tumor & & & 1.000 \\
\hline Yes & $2(1.5 \%)$ & $\mathrm{I}(0.7 \%)$ & \\
\hline No & $96(70.1 \%)$ & $38(27.7 \%)$ & \\
\hline Other Lesion & & & 0.2314 \\
\hline Yes & $13(9.5 \%)$ & $2(1.5 \%)$ & \\
\hline No & $85(62.0 \%)$ & $37(27.0 \%)$ & \\
\hline
\end{tabular}

\section{Discussion}

The prevalence of H. pylori in our series is $71.5 \%$ and confirms that Benin is a developing country like most African countries, some South American and West Asian countries. ${ }^{1,2}$ There was no significant variation in the presence of $H$. pylori by age and socio-economic factors in our series, contrary to the results of Hunt et al. ${ }^{1}$ Sokpon et al. ${ }^{9}$ and Odigie et al. ${ }^{21}$ reported a significant association with female sex, whereas most African studies did not find a statistically significant

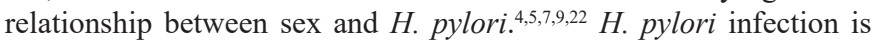
frequently associated with certain socio-demographic factors such as living conditions (promiscuity, access to drinking water), level of education, lifestyle, and occupation..$^{1,4,7,12,21,23}$ None of these factors classically associated with $\mathrm{H}$ pylori infection were found in our series. This could be explained by the fact that most of the patients included were living in urban areas in Cotonou.

Approximately $1 / 3$ of the previously treated patients still had $H$. pylori, with the highest rate in the batch of those who used amoxicillin and metronidazole in combination with PPI. Indeed, the only effective treatment currently available for $H$. pylori infection involves the use of antibiotics. This observed result could be related to resistance or recontamination. The main mechanisms for the development of antibiotic resistance in $H$. pylori include mutations that alter the ability of antibiotics to bind to ribosomes and interfere with protein synthesis; mutations that affect DNA replication and transcription and modify penicillin-binding proteins involved in peptidoglycan biosynthesis. ${ }^{24}$ This resistance is therefore multifactorial and depends not only on the possibility of the germ to mutate but also on the free access to antibiotics allowing an abusive and uncontrolled use that would nest the mutation at the gene level. ${ }^{7}$ Resistance to metronidazole has been reported in most African countries ${ }^{1,23}$ and may be due to open access and misuse. This study did not assess the level of antibiotic resistance of $H$ pylori.

The endoscopic aspects of the lesions were dominated by the pangastritis aspect in our study. This finding corroborates most of the studies carried out in Africa on this subject. ${ }^{9,20,22}$ Gastritis is thought to result from an inflammatory and immunological response induced by $H$. pylori. ${ }^{1,25}$ In patients infected with $H$. pylori in our series, pre- neoplastic lesions were noted such as gastric atrophy in $7.1 \%$ of cases, intestinal metaplasia in $7.69 \%$ of cases and low grade dysplasia in $8.57 \%$ of cases. These values are slightly lower than those reported by Darré et al. ${ }^{26}$ in Togo, where $99 \%$ of $\mathrm{H}$. pylori positive patients had glandular atrophy and $85 \%$ had intestinal metaplasia. ${ }^{26}$ Sokpon found a statistically significant relationship between these lesions (fundal and anal atrophy, fundal metaplasia) and H. pylori. ${ }^{9}$ The nearconstancy of chronic gastritis in southern countries is probably related to the early onset of H. pylori infection, which occurs most often in childhood. ${ }^{13}$

Our study has the interest to evaluate the prevalence of $H$. pylori in Benin using histology which offers the advantage of good sensitivity and specificity, but also to type the associated gastritis for a good patient follow-up (therapeutic and endoscopic evaluation of the response to treatment). However, its accessibility poses a problem due to its cost, which is often not accessible to everyone. The main limitation of this study is the small number of patients included.

\section{Conclusion}

The prevalence of $H$. pylori is high in our series, at $71.5 \%$. It is not significantly associated with any of the socio-demographic factors studied, nor with any co-morbidity. Gastric atrophy was the most common pre-neoplastic lesion. The lack of difference between pretreated patients and those naïve to any eradicant treatment raises the suspicion of either a high level of antibiotic resistance or frequent re-infections in the study population. It is desirable to conduct studies to measure the sensitivity of $H$. pylori infection to antibiotics in our country.

\section{Acknowledgments}

None.

\section{Conflicts of interest}

Author declares that there are no conflicts of interest.

\section{Funding}

None. 


\section{References}

1. Hunt RH, Xiao SD, Megraud F, et al. Helicobacter Pylori in developing countries. World Gastroenterology Organisation Global Guideline. $J$ Gastrointestin Liv Dis. 2011;20(3):299-304.

2. Hooi JKY, Lai WY, Ng WK, et al. Global prevalence of helicobacter pylori infection:systematic review and meta-analysis. Gastroenterology. 2017;153(2):420-429.

3. Gashau W, Adamu AS. Blind Helicobacter pylori treatment in dyspeptics in a high prevalence area. Int J Cur Res Rev. 2020;12(4):2-7.

4. Awuku YA, Simpong DL, Alhassan IK, et al. Prevalence of Helicobacter pylori infection among children living in a rural setting in sub-Saharan Africa. BMC Public Health. 2017;17(1):360.

5. Lawson-Ananissoh LM, Bouglouga O, Bagny A, et al. Epidemiological profile of peptic ulcers at the Lomé campus hospital and university center (Togo). J Afr Hépatol Gastroentérol. 2015;9(3):99-103.

6. Bossali F, Deby G, Ahoui-Apendi CR et al. Study of the management of helicobacter pylori infection in the cities of pointe-noire and brazzaville in 2015. Ann Univ M Ngouabi. 2017;17(1):1-9.

7. Ntagirabiri R, Harerimana S, Makuraza F, et al. Helicobacter pylori in Burundi: first assessment of endoscopic prevalence and eradication. J Afr Hépatol Gastroentérol. 2014;8:217-222.

8. Alboraie M, Elhossary W, Aly OA, et al. Egyptian recommendations for management of Helicobacter pylori infection: 2018 report. Arab J Gastroenterol. 2019;20(3):175-179.

9. Sokpon M, Salihoun M, Lahlou L, et al. Predictors of Helicobacter pylori ( Hp ) infection in chronic gastritis: about a Moroccan study. J Afr Hépatol Gastroentérol. 2016;10(4):203-207.

10. Kasmi H, Doukani K, Ali A, et al. Epidemiological Profile of Helicobacter pylori Infection in Patients with Digestive Symptoms in Algeria. Journal of Epidemiology and Global Health. 2020.

11. van Blankenstein $\mathrm{M}$, van Vuuren AJ, Looman CW, et al. The prevalence of Helicobacter pylori infection in the Netherlands. Scand J Gastroenterol. 2013;48(7):794-800.

12. Mégraud F. When and how do you get infected with Helicobacter pylor ?Gastroenterol Clin Biol. 2003;27:374-379.

13. Calvet X, Ramirez Lázaro MJ, Lehours $P$, et al. Diagnosis and epidemiology of Helicobacter pylori infection. Helicobacter. 2013;18:5-11.
14. De Korwin JD. Nouvelles recommandations pour le diagnostic et le traitement de l'infection à Helicobacter pyloriNew recommendations for the diagnosis and the treatment of Helicobacter pylori infection. La Presse Médicale. 2013;42(3):309-317.

15. IARC. Working Group on the Evaluation of Carcinogenic Risks to Humans. Helicobacter pylori. In: Schistosomes, liver flukes, and Helicobacter pylori. Lyon: IARC; 1994. p. 177-240.

16. Pohl D, Keller PM, Bordier V, et al. Review of current diagnostic methods and advances in Helicobacter pylori diagnostics in the era of next generation sequencing. World J Gastroenterol. 2019;25(32):4629-4660.

17. Michaud L, Gottrand F. Infection à Helicobacter pylori: Quelle prise en charge en 2013. Réalités pédiatriques. 2013;181:35-38.

18. Seidou F, Kpossou R, Akpo W, et al. Gastrites at Helicobacter pylori: about 159 cases in two laboratory of anatomopathology of Cotonou. J Afr Chir Digest. 2018;18(1):2332-2337.

19. Kodjoh N, Hountoundji A, Addra B. Apport de l'endoscopie au diagnostic des affections oeso-gastro-duodénales en milieu tropical:Expérience béninoise à propos de 930 examens. Ann Gastroenterol Hepatol. 1991;27(6):261-267.

20. Hountondji A, Addra B, Kodjoh N, et al. Helicobacter pylori and gastric diseases in Benin. Journal of the Society of Clinical Biology of Benin. 1996;3:71-76

21. Odigie AO, Adewole AJ, Ekunwe AA. Prevalence and factors associated with Helicobacter pylori infection among treatment naïve dyspeptic adults in University of Benin Teaching Hospital, Benin City, Nigeria. Afr J Clin Exper Microbiol. 2020;21(2):97-105.

22. Hafidi R, Oubaha S, El Gamrani Y, et al. Helicobacter pylori infection: epidemiological, clinical and endoscopic aspects. $J$ Afr Hépatol Gastroentérol. 2013;7:74-77.

23. Smith S, Fowora M, Pellicano R. Infections with Helicobacter pylori and challenges encountered in Africa. World $J$ Gastroenterol. 2019;25(25):3183-3195.

24. Zanotti G, Cendron L. Structural Aspects of Helicobacter pylori Antibiotic Resistance. Adv Exp Med Biol. 2019;1149:227-241.

25. Sibony M, Jones NL. Recent advances in Helicobacter pylori pathogenesis Curr Opin Gastroenterol. 2012;28(1):30-35.

26. Darré T, Amégbor K, Bagny A, et al. Histo-epidemiologic profile of chronic gastritis and infection with Helicobacter pylori: about 296 cases of biopsies in Togo. J Afr Chir Digest. 2013;13(1):1426-1430. 